\title{
Composição química e toxicidade frente Aedes aegypti L. e Artemia salina Leach do óleo essencial das folhas de Myrcia sylvatica (G. Mey.) DC.
}

ROSA, C.S. ${ }^{1 *}$; VERAS, K.S.'; SILVA, P.R.'; LOPES NETO, J.J.'; CARDOSO, H.L.M.'; ALVES, L.P.L.'; BRITO, M.C.A.'; AMARAL, F.M.M.'; MAIA, J.G.S.2; MONTEIRO, O.S. ${ }^{3}$; MORAES, D.F.C. ${ }^{1}$

1Universidade Federal do Maranhão - Departamento de Farmácia, São Luís, MA, Brasil, 2Universidade Federal do Oeste do Pará - Programa de Pós-Graduação em Recursos Naturais da Amazônia, 68035-110 Santarém, PA, Brasil. 'Universidade Federal do Maranhão - Departamento de Química, Centro de Ciências Exatas e Tecnológicas, São Luís, MA, Brasil. *Autor para correspondência: carlianefarmaufma@hotmail.com

RESUMO: A dengue está entre as doenças virais de propagação vetorial mais importante no mundo, causando sérios impactos de morbidade e mortalidade. Desta forma, o presente trabalho teve como objetivo analisar a composição química e a toxicidade do óleo essencial de Myrcia sylvatica (G. Mey) D.C. frente Aedes aegypti e Artemia salina. Folhas de M. sylvatica foram coletadas no Parque Nacional da Chapada das Mesas, no município de Carolina (MA) no mês de fevereiro de 2012. O óleo foi obtido por hidrodestilação e sua composição química foi determinada por cromatografia gasosa acoplada à espectrometria de massa (CG/EM). $O$ bioensaio frente Artemia salina e às larvas de $3^{\circ}$ estádio de Aedes aegypti foram realizados em diferentes concentrações. Os dados de mortalidade foram avaliados por regressão linear para determinar os valores de $\mathrm{CL}_{50}$. Obteve-se $0,5 \%$ de rendimento, sendo o (E)-cariofileno $\mathrm{O}$ constituinte majoritário. O óleo essencial apresentou uma $\mathrm{CL}_{50}=79,44 \mu \mathrm{g} / \mathrm{mL}$ frente $A$. salina, sendo considerado altamente tóxico. No entanto, este óleo não demonstrou efeito sobre as larvas de $A$. aegypti. Considerando que o teste de Artemia salina tem correlação com atividades biológicas de grande interesse terapêutico como antitumoral, o óleo essencial das folhas de $M$. sylvatica demonstrou potencial para desenvolvimento de produtos farmacêuticos.

Palavras-chave: Myrcia sylvatica, óleo essencial, Aedes aegypti, larvicida, Artemia salina.

\begin{abstract}
Chemical composition and toxicity against Aedes aegypti L. and Artemia salina Leach of the essential oil from Myrcia sylvatica (G. Mey.) DC. leaves. Dengue is among the most important viral diseases of vector spread in the world, causing serious impacts of morbidity and mortality. Thus, this study aimed to analyze the chemical composition and toxicity of the Myrcia sylvatica (G. Mey.) DC essential oil against Aedes aegypti and Artemia salina Leach. Leaves of $M$. sylvatica. were collected in the Tables Chapada National Park, in the municipality of Carolina (MA) in february 2012. The oil was obtained by hydrodistillation and their chemical composition was determined by GC / MS. The bioassay front and Artemia salina larvae of the $3^{\circ}$ stage of Aedes aegypti were performed at different concentrations. Mortality data were evaluated by linear regression to determine the $L C_{50}$. Was obtained $0.5 \%$ yield values, and $(E)$-caryophyllene the major constituent. The essential oil showed a $\mathrm{LC}_{50}=$ $79.44 \mathrm{mg} / \mathrm{mL}$ front $A$. saline and is considered highly toxic. However, this oil showed no effect on larvae of $A$. aegypti. Whereas the brine shrimp test has regard to several biological activities, as antitumoral property, the essential oil from the leaves of $M$. sylvatica demonstrated potential for development of medicines.
\end{abstract}

Keywords: Myrcia sylvatica, essential oil, Aedes aegypti, larvicide, Artemia salina.

\section{INTRODUÇÃO}

As plantas vem sendo utilizadas com fins medicinais desde tempos remotos. Segundo a Organização Mundial de Saúde, $80 \%$ da população de países em desenvolvimento utiliza plantas na atenção primária à saúde. No Brasil, acredita-se que $90 \%$ da população já utilizou alguma planta 
medicinal. A rica biodiversidade brasileira e as heranças culturais de índios, negros e europeus contribuem para que as plantas sejam consideradas uma área estratégica para o desenvolvimento do país (Boas \& Gadelha, 2007; Joharchi \& Amiri, 2012).

A dengue, infecção viral transmitida por mosquitos do gênero Aedes, é considerada uma das maiores preocupações mundiais de Saúde Pública (Who, 2004), estimando-se que a doença atinja aproximadamente 390 milhões de pessoas por ano (Bhatt et al., 2013). Atualmente, constatou-se que esses mosquitos são também transmissores de outros vírus como: Chikungunya vírus (CHIKV) e Zika vírus (ZIKV). Essas viroses vem despertando interesse de pesquisadores, pois CHIKV causa sintomas parecidos com a dengue, no entanto com dores mais severas (Brasil 2014a; Brasil, 2014b), enquanto ZIKV provoca sintomas fáceis de controlar, mas que em alguns paciente é observado o aparecimento de síndrome neurológica e doenças autoimunes, sendo referida a correlação com o vírus (Zanluca et al., 2015).

A inexistência de vacinas contra estas doenças agrava a situação e concentra seu controle na eliminação de seus vetores através da aplicação de inseticidas inorgânicos e orgânicos sintéticos. No Brasil, o vetor desses vírus é a fêmea do mosquito Aedes aegypti L. (Diptera: Culicidae) (Braga \& Valled; 2007, Who, 2009).

No entanto, o emprego de compostos orgânicos sintéticos nesse controle, por apresentarem um amplo espectro de ação e um efeito residual prolongado, fez surgir uma variedade de problemas ambientais e toxicológicos (Santos et al., 2006). Todos esses fatores alertaram a comunidade científica na busca de formas alternativas para o controle dos insetos vetores (Barreto, 2005).

Na perspectiva de desenvolver produtos no controle de pragas, principalmente que transmitam doenças, o uso de plantas com atividade inseticida e larvicida tem se mostrado promissor, considerando que estes organismos são ricos em substâncias bioativas, principalmente oriundas do metabolismo secundário, que são específicas para cada espécie, ou seja, não apresentam distribuição generalizada (Barreto, 2005; Rodrigues, 2012; Silva, 2006; Simas et al., 2004).

Entretanto, o uso de plantas não se restringe ao controle de doenças. Espécies vegetais são de grande importância para a indústria farmacêutica para a produção de fitofármacos, a partir do isolamento de substâncias com ação farmacológica ou para a produção de fitoterápicos, que agem principalmente por ação terapêutica sinérgica (fitocomplexo) e, ainda, muito utilizada na indústria de cosmético, materiais de limpeza e de higiene (Silveira et al., 2008) .

É importante ressaltar que o uso de plantas para qualquer um dos fins citados acima, exige a realização de ensaios de toxicidade para verificar a segurança nessa utilização. Nesse propósito, tem sido estimulado o desenvolvimento de ensaios in vitro para determinar a possível toxicidade das plantas e seus produtos derivados, em virtude das campanhas de redução e/ou eliminação do uso de animais de laboratório (Andrade et al., 2002).

Dentre esses testes, merece destaque o bioensaio com Artemia salina Leach que constitui um microcrustáceo cosmopolita de água salgada, com facilidade de reprodução, o que favorece seu uso em ensaios de toxicidade, podendo, ainda indicar possíveis ações biológicas como anticancerígena, inseticida, moluscicida e antifúngica (Luna et al., 2005).

Os óleos essenciais, produtos provenientes do metabolismo secundário dos vegetais, são considerados misturas de constituintes, sendo formados principalmente por monoterpenos, sesquiterpenos e fenilpropanoides. Estes óleos vem despertando amplo interesse de vários grupos de pesquisa devido à diversidade de atividades biológicas relacionadas a eles, como: antibacteriana, antifúngica, larvicida, ovicida, inseticida, antioxidante, dentre outras (Donato \& Morretes, 2011; Guimarães et al., 2011; Limberger et al., 2004; Porto et al., 2008; Sherer et al., 2009; Simas et al., 2004).

A família Myrtaceae vem sendo reconhecida pelas investigações relativas à composição química de suas espécies e atividades biológicas, principalmente pela presença de óleos essenciais (Aciole, 2001). Entre as espécies desta família, destaca-se Myrcia sylvatica (G.Mey.) DC., conhecida como murta, murtinha ou pedra-ume-caá, com ampla distribuição na América do Sul, sendo reconhecida pelo seu aroma adocicado (Almeida, 2014; Trópicos, 2013; Zoghbi et al., 2002).

Na cidade de Belém (PA), M. sylvatica é comercializada como pedra-ume-caá e as folhas são utilizadas na forma de chás, com indicações para o tratamento de diabetes, diarréia, afta, inflamação intestinal e hemorragia ou utilizada em forma de banhos de assento, por meio da maceração das folhas, para tratar inflamações uterinas (Silva, 2012).

Apesar de ser amplamente utilizada pela população, poucos são os estudos desenvolvidos com essa espécie, constituindo uma lacuna para a descoberta de substâncias e produtos de interesse ao homem, para uso pelas indústrias farmacêuticas, de cosméticos, dentre outras.

Considerando as características da família Myrtaceae, com riqueza de óleos essenciais bioativos e a necessidade de estudo das espécies 
da nossa flora, buscando soluções para problemas de saúde pública, o presente trabalho objetiva caracterizar os constituintes químicos do óleo essencial das folhas de M. sylvatica, assim como avaliar sua toxicidade frente Aedes aegypti e Artemia salina.

\section{MATERIAL E MÉTODOS \\ Coleta do Material}

As folhas de M. sylvatica foram coletadas no Parque Nacional da Chapada das Mesas, no município de Carolina (MA) em fevereiro de 2012. A autorização de coleta, $n^{\circ}$ 280007-1, foi concedida pelo Sistema de Autorização e Informação em Biodiversidade (SISBIO), órgão do Ministério do Meio Ambiente (MMA). Exsicatas dessa espécie vegetal foram depositadas no Herbário João Murça Pires do Museu Paraense Emílio Goeldi, onde se encontra registrada sob o código L-3149.

\section{Extração do Óleo Essencial}

As folhas foram dessecadas a temperatura ambiente e trituradas em moinho de facas, obtendose um pó classificado como medianamente rasurado (4 mm), segundo a Farmacopeia Brasileira (2010). Em seguida 200 gramas do material foram submetidos à hidrodestilação (Farmacopeia Brasileira, 2010). O óleo essencial foi coletado, seco com sulfato de sódio anidro $\left(\mathrm{Na}_{2} \mathrm{SO}_{4}\right)$ e acondicionado em frasco âmbar, hermeticamente fechado. O rendimento percentual foi determinado (Coutinho et al., 2007).

\section{Análise da Composição Química do Óleo Essencial}

A determinação química do óleo foi feita por cromatografia gasosa acoplada a espectrometria de massa (CG/EM)/Hewlett Packard Modelo 5971, sob as seguintes condições: coluna de dimetilpolissiloxano DB-1 (30 m x 0,25 mm, espessura do filme $0,1 \mu \mathrm{m})$, gás de arraste-hélio (vazão de $1 \mathrm{ml} / \mathrm{min}$ ), temperatura de injeção $-250^{\circ} \mathrm{C}$, temperatura do detector $-200^{\circ} \mathrm{C}$; sendo que a taxa de aquecimento da coluna entre a faixas de $180-250^{\circ} \mathrm{C}$ foi de $10^{\circ} \mathrm{C} / \mathrm{min}$. A identificação dos componentes do óleo foi realizada comparando seus dados com os de substâncias autênticas existentes em biblioteca de referência (Adams, 2007; Nist, 2005). A porcentagem relativa dos componentes foi calculada usando a área do pico de cada substância no cromatograma.

\section{Ensaio Frente Artemia salina}

O teste de toxicidade frente Artemia salina foi realizado segundo a metodologia de Meyer et al. (1982) com algumas alterações. Após a eclosão dos ovos e o tempo para as larvas alcançarem o estádio de metanáuplio (24 horas), as larvas foram transferidas para recipientes plásticos, ficando 10 larvas em cada receptáculo. $O$ teste foi feito em triplicata, contendo solução salina e a respectiva amostra nas concentrações de 10,100 e $1000 \mu \mathrm{g} /$ $\mathrm{mL}$. O controle positivo foi feito com dicromato de potássio $\left(\mathrm{K}_{2} \mathrm{Cr}_{2} \mathrm{O}_{7}\right)$ a $10 \mu \mathrm{g} / \mathrm{mL}$ e o negativo com uma solução de salina e dimetlsulfóxido (DMSO) na concentração de $0,01 \%$. Após 24 horas de contato, contaram-se os animais mortos.

\section{Ensaio Frente às Larvas de Aedes aegypti}

Foram utilizadas larvas de $A$. aegypti, cujos ovos foram capturados em armadilhas nos bairros da Santa Clara, Cohatrac IV e Sá Viana, na cidade de São Luís (MA), sendo posteriormente transferidos para água destilada, onde as larvas foram alimentadas com ração para gato triturada para atingir o terceiro estádio de desenvolvimento larval. A identificação das larvas foi feita de acordo com as características da literatura (Consoli \& Oliveira, 1994; Santos, 2008). Os ensaios biológicos foram realizados segundo metodologia preconizada pela World Health Organization (WHO) (2009) com adaptações. O óleo essencial de $M$. sylvatica foi testado nas concentrações de 25, 100, 250, 500 $\mu \mathrm{g} / \mathrm{mL}$, sendo realizado teste em triplicata para cada concentração. A solução do óleo essencial foi preparada usando DMSO $0,01 \%$. O controle negativo foi feito com DMSO $0,01 \%$ em água destilada e o controle positivo com o larvicida sintético Temephós ${ }^{\otimes}$ a $3 \mu \mathrm{g} / \mathrm{mL}$. Depois foram feitas as leituras das larvas sobreviventes em 24 e 48 h após o inicio do teste.

\section{Análise Estatística}

A ação larvicida foi expressa em $\mathrm{CL}_{50}$, concentração letal capaz de matar $50 \%$ das larvas, com limite de confiança de $95 \%$, por meio do método de regressão linear, através do gráfico do logaritmo da concentração das amostras versus a percentagem de mortos e determinados através da análise de probitos, usando programa SPSS 13.0.

\section{RESULTADOS}

O óleo essencial das folhas de $M$. sylvatica apresentou rendimento de $0,5 \%$ e o cromatograma (Figura 1) permitiu identificar 22 constituintes (Tabela 1), representando $99,59 \%$ do conteúdo total desse óleo volátil, com predominância de sesquiterpenos. O (E)-cariofileno foi o componente majoritário com $45,88 \%$, seguido por 14-hidróxi(Z)-cariofileno (10,15\%), $\beta$-seleneno $(5,97 \%)$ e a selina-3,11-diene $(5,43 \%)$ (Tabela 1).

Em relação aos ensaios biológicos, o teste

Rev. Bras. PI. Med., Campinas, v.18, n.1, p.19-26, 2016. 


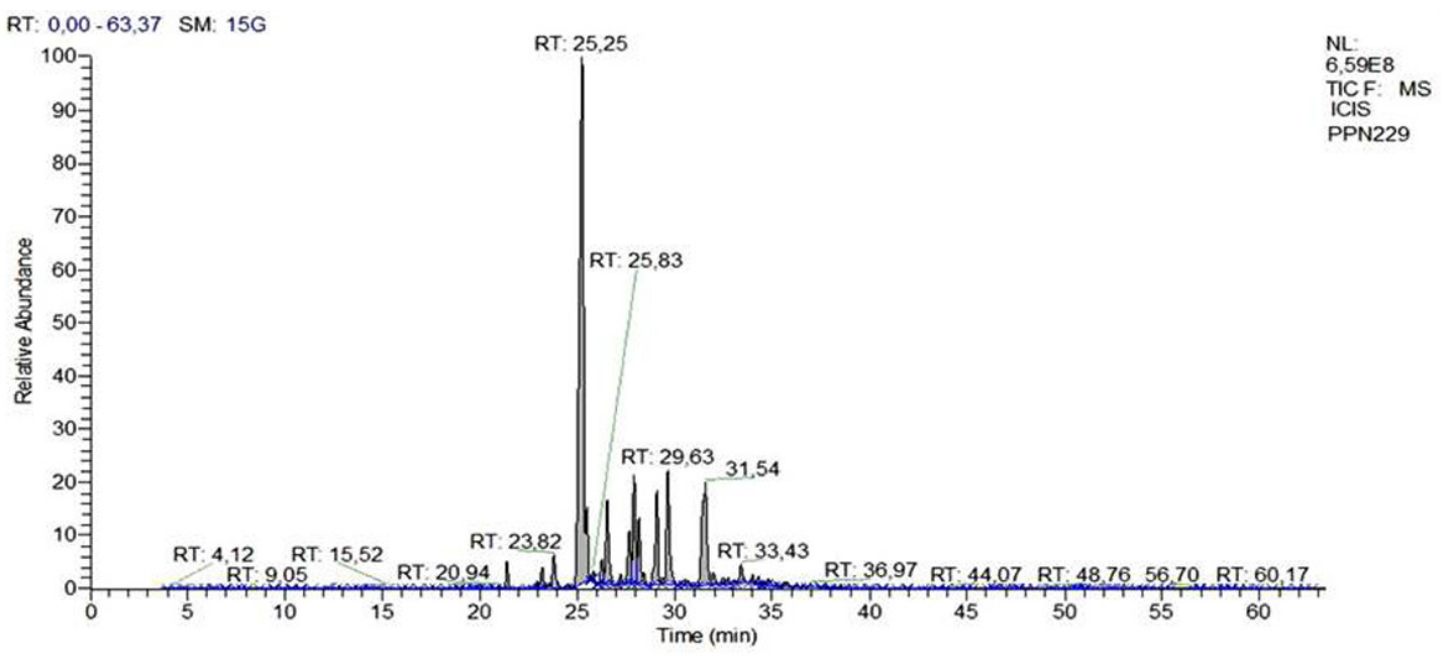

FIGURA 1. Cromatograma do óleo essencial das folhas de Myrcia sylvatica, analisado por cromatografia gasosa. Condições experimentais descritas no texto.

TABELA 1. Constituintes químicos do óleo essencial das folhas de Myrcia sylvatica.

\begin{tabular}{|c|c|c|c|}
\hline $\mathrm{T}_{\mathrm{RET}}$ & $\mathrm{RI}_{\text {lit }}$ & Constituintes & $\mathrm{A} \%$ \\
\hline 25,25 & 1431 & (E)-Cariofileno & 45,88 \\
\hline 31,54 & 1588 & 14-Hidróxi-(Z)-Cariofileno & 10,15 \\
\hline 27,91 & 1496 & $\beta$-Seline & 5,97 \\
\hline 29,08 & 1526 & Selina-3,7(11)-dieno & 5,43 \\
\hline 26,55 & 1463 & $\alpha$-Humeleno & 4,83 \\
\hline 28,16 & 1502 & Germacreno-B & 4 \\
\hline 27,66 & 1490 & a-Selinene & 3,23 \\
\hline 23,82 & 1396 & $\beta$-Elemeno & 2,09 \\
\hline 21,37 & 1338 & Biciclogermacreno & 1,31 \\
\hline 33,43 & 1639 & Espatulenol & 1,31 \\
\hline 26,26 & 1456 & Sibirene & 1,27 \\
\hline 23,22 & 1381 & a-Copaene & 0,96 \\
\hline 30,56 & 1563 & Germacreno-B & 0,44 \\
\hline 34,81 & 1676 & Cariofileno -14-hidroxi-9-epi-(E) & 0,43 \\
\hline 22,93 & 1375 & $\alpha$-Ylangene & 0,35 \\
\hline 32,76 & 1621 & Amorpha-4,7(11)-dieno-2-a-hidróxi & 0,35 \\
\hline 36,97 & 1727 & Amorpha-4,9-dieno-7,14-Anidro & 0,28 \\
\hline 35,77 & 1701 & $\alpha$-Eudesmol-10-Epi & 0,25 \\
\hline 30,26 & 1556 & $\beta$-Costol & 0,11 \\
\hline 36,29 & 1712 & Amorpha-4,7(11)-dieno-2-a-Hidróxi & 0,11 \\
\hline 22 & 1353 & a-Cubebene & 0,06 \\
\hline 38,37 & 1757 & Nootkatol & 0,06 \\
\hline
\end{tabular}

Tempo de Retenção (TRET); Índice de Retenção $\left(\mathrm{RI}_{\mathrm{lit}}\right)$. Porcentagem relativa da área do pico no cromatograma $(\mathrm{A} \%)$

frente $A$. salina mostrou uma $\mathrm{CL}_{50}$ de $79,44 \mu \mathrm{g} / \mathrm{mL}$. No bioensaio com larvas de Aedes aegypti, não foi observada mortalidade destas larvas até a maior concentração testada ( $500 \mu \mathrm{g} / \mathrm{mL})$, mesmo na leitura de 48 horas de exposição, indicando que o óleo essencial de M. sylvatica não apresentou potencial tóxico frente a essa larva. Dessa forma, não foi possível calcular a $\mathrm{DL}_{50}$.

Os controles positivos mostraram efetividade de $100 \%$, enquanto que os controles negativos não apresentaram mortalidade, o que demonstra que o solvente usado é inofensivo e 
que as atividades apresentadas estão relacionadas somente à amostra testada.

\section{DISCUSSÃO}

A predominância de sesquiterpenos cíclicos assemelha-se aos obtidos com outras espécies de Myrtaceae americanas previamente analisadas, cuja predominância de desses compostos é uma constante, principalmente dos grupos do cariofileno e germacrano (Limberger et al., 2004). Na literatura, verifica-se pelos menos quatro quimiotipos para a espécie analisada: $\beta$-cariofileno, selin-11-en-4- $\alpha$ ol, cis-calameneno e o espatulenol (Zoghbi et al., 2002). A análise química do óleo permite classificar a espécie M. sylvatica, coletada em Carolina-MA, como pertencente ao quimiotipo $\beta$-cariofileno, visto que seu constituinte principal foi o $(E)$-cariofileno e estes são sinônimos (Adams, 2007).

O $\beta$-cariofileno, espatulenol, $\beta$-elemeno, $\alpha$-humuleno e o $\gamma$-eudesmol, componentes do óleo essencial de $M$. sylvatica tem demonstrado diversas atividades biológicas, dentre elas atividade anticarcinogênica, por meio de vias apoptóticas e inibição de proliferação celular de células tumorais (Alcântara et al., 2010; Lunguino, 2012).

Comparando-se os constituintes obtidos em nosso estudo com os já descritos na literatura para esta espécie, verificamos diferenças quanto aos marcadores químicos (Limberger et al., 2004; Zoghbi et al., 2003).

Alguns autores sugerem que o polimorfismo químico de óleos essenciais pode estar relacionado à influência de fatores ambientais, tais como temperatura, umidade, duração e intensidade das radiações solares; fatores edáficos e variabilidade genética (Cerqueira et al., 2009; Duarte, 2012; Sá et al., 2012; Sabino et al., 2012).

Segundo os critérios de Dolabella (1997), o óleo de M. sylvatica é classificado como altamente tóxico. Em estudo toxicológico das folhas de $M$. sylvatica frente a Artemia salina, Batista et al. (2010) obtiveram $\mathrm{DL}_{50}$ de $38,1 \mu \mathrm{g} / \mathrm{mL}$, pode ser classificado como potencialmente tóxico.

Embora a alta toxicidade de um produto frente às larvas de $A$. salina tenha correlação com ensaio de toxicidade in vivo, podendo ser considerado um bom teste para prever toxicidade oral de produtos (Parra et al., 2001), este teste também é um bom indicativo para potencial atividade biológica, como antimicrobiana e anticancerígena (Harada, 2009; Kanwar, 2007; Lunguino, 2012). A dose efetiva $\left(\mathrm{DE}_{50}\right)$ em teste com o microcrustáceo A. salina é geralmente dez vezes a concentração necessária para inibir $50 \%$ do crescimento celular $\left(\mathrm{Cl}_{50}\right)$ em testes antitumorais (McLaughlin et al., 1998), transformando estes ensaio em uma alternativa aos testes realizados em animais.

De acordo com David et al. (2001), a classificação de substâncias puras obtidas de extratos de plantas, quanto à sua atividade citotóxica em A. salina, correlacionando com atividade anticancerígena, pode ser assim atribuídas: substâncias que apresentam $\mathrm{DE}_{50}>1000 \mu \mathrm{g} / \mathrm{mL}$ são consideradas inativas e aquelas com $\mathrm{DE}_{50}<100 \mu \mathrm{g} /$ $\mathrm{mL}$ são muito ativas, comparáveis à camptotecina e ao sulfato de vincristina, substâncias usadas no tratamento de leucemia (Schripsema et al., 2004).

Siqueira et al. (1998) observaram a validade e confiabilidade do bioensaio da $A$. salina, em estudo de toxicidade de frações de Unonopsis lindmanii que continham substâncias reconhecidamente ativas sobre células tumorais in vitro (Ceplenau, 1993; Valter et al., 2008).

El-Mensshawi et al. (2010) enfatizaram a representatividade do ensaio com $A$. salina, sendo considerado, por esses autores, um teste robusto para ser empregado como pré-screning em investigação de atividade terapêutica contra tumores sólidos.

A possibilidade de se prever uma atividade específica de uma determinada substância a partir de um bioensaio geral facilita o direcionamento de estudos de prospecção de novas drogas (Harada, 2009; Kanwar, 2007; Lunguino, 2012).

Vários óleos essências e seus componentes aromáticos individuais já demonstraram atividade supressora tumoral quando testado em um significante número de linhagens tumorais humanas, incluindo tumor hepático, câncer de mama, leucemias, câncer de colón, dentre outras (Edres, 2007; Lunguino, 2012).

Em relação ao teste de atividade larvicida contra Aedes aegypti, o óleo de M. sylvatica não mostrou ação tóxica em nenhuma das concentrações utilizadas, apesar de haver indicação que óleos com padrão sesquiterpênico, teoricamente, são mais ativos para o controle de larvas de A.aegypti (Santos et al., 2006).

No entanto, esta teoria pode ser questionada, visto que estudos com outras espécies da família Myrtaceae como M. guianensis, M. Iundiana, M. ovata que apresentaram padrão sesquiterpênico, comprovaram que as duas primeiras apresentaram atividade moderada, enquanto que $M$. ovata não apresentou potencial larvicida (Fontes et al., 2011; Monteiro et al., 2011). Desta forma, a presença de um padrão sesquiterpeno não é garantia da atividade larvicida. Padrão monoterpênico pode também apresentar atividade larvicida contra $A$. aegypti como mostrado para os óleos de Hyptis martiussi, Eucapliptus sp e Syzigium aromaticum, que apresentaram uma $\mathrm{CL}_{50}$ bem próxima daqueles com padrão sesquiterpenos (Costa et al., 2008;

Rev. Bras. PI. Med., Campinas, v.18, n.1, p.19-26, 2016. 
Santos et al., 2006; Simas et al., 2004).

Para entender melhor a relação entre o óleo essencial e a sua atividade larvicida, alguns autores testaram isoladamente os principais componentes dos óleos essenciais. Na maior parte dos estudos, observou-se que todo o óleo essencial foi mais ativo do que os seus compostos isolados (Dias \& Moraes, 2014). Os sesquiterpenos oxigenados $\beta$-eudesmol e óxido de cariofileno, que são os principais compostos ativos dos óleos essenciais da Guatteria friesiana e Guatteria blepharophylla, respectivamente não apresentaram atividade quando testados isoladamente em comparação ao óleo (Cheng et al., 2009). Isto pode ser explicado pelas interações entre os constituintes presentes nos óleos (Aciole, 2001; Santos et al., 2006). Em alguns casos, a bioatividade da mistura é mais elevada do que os dos compostos purificados.

Em estudo realizado por Silva et al. (2008), $\beta$ - cariofileno e óxido de cariofileno foram identificados como os principais compostos do óleo essencial de folhas de Hyptis pectinata (L.) Poit, exibindo um valor de $\mathrm{CL}_{50} 1.202 \mathrm{mg} / \mathrm{L}$ e $125 \mathrm{mg} / \mathrm{L}$ respectivamente, enquanto que o valor de $\mathrm{CL}_{50}$ do oléo foi de $366 \mathrm{mg} / \mathrm{L}$. Cheng et al. (2009) estudando o óleo essencial de folhas de Cryptomeria japonica (Thunb. Ex L.F.) D.Don, também constataram que o óleo $\left(\mathrm{CL}_{50}=28,4 \mathrm{mg} / \mathrm{L}\right)$ foi mais tóxico para $A$. aegypti do que o seu constituintes majoritários 16-kaurenos $\left(\mathrm{CL}_{50}=57,0 \mathrm{mg} / \mathrm{L}\right)$ e elemol $\left(\mathrm{CL}_{50}>\right.$ $100,0 \mathrm{mg} / \mathrm{L})$, ambos presentes na amostra em proporções que se aproximam de $20 \%$, sugerindo que o compostos minoritários 3-careno $\left(\mathrm{CL}_{50}=25,3\right.$ $\mathrm{mg} / \mathrm{L})$, terpinoleno $\left(\mathrm{CL}_{50}=32,1 \mathrm{mg} / \mathrm{L}\right)$, $\alpha$-terpineno $\left(\mathrm{CL}_{50}=28,1 \mathrm{mg} / \mathrm{L}\right)$, e $\mathrm{\gamma}$ - terpineno $\left(\mathrm{CL}_{50}=26,8 \mathrm{mg} / \mathrm{L}\right)$ também contribuem para a atividade larvicida. Assim, evidencia-se que a classe dos compostos majoritários de um óleo essencial, nem sempre é um fator primordial na determinação de sua atividade, pois seus constituintes podem agir por sinergismo e os componentes minoritários podem influenciar na atividade biológica do óleo.

Com os resultados obtidos nesse estudo, podemos concluir que o óleo essencial de $M$. sylvatica, coletada em Carolina-MA, não demonstrou ação sobre as larvas de Aedes aegypti e apresentou forte toxicidade no bioensaio com Artemia salina, indicando possível potencial para o desenvolvimento biotecnológico de formulações farmacêuticas, com especial atenção à ação antineoplásica.

\section{AGRADECIMENTOS}

Ao Conselho Nacional de Desenvolvimento Científico e Tecnológico (CNPq) e à Fundação de Amparo à Pesquisa e Desenvolvimento Científico do Maranhão (FAPEMA) pelo apoio financeiro e à
Universidade Federal do Maranhão (UFMA) pela concessão de bolsas de iniciação científica

\section{REFERÊNCIAS}

ACIOLE, S.D.G. Avaliação da atividade inseticida dos óleos essenciais das plantas Amazônicas Annonaceae, Boraginaceae e de Mata Atlântica Myrtaceae como alternativa de controle as larvas de Aedes aegypti (Linnaeus, 1762) (Diptera Culicidae). 2001. 72 pg. Dissertação (Mestrado em Biologia Humana e Ambiente) - Universidade de Lisboa, Lisboa.

ADAMS, R.P. Identification of essential oil components by gas chromatography/mass spectrometry. 4 . ed. Carol Stream: Allured, 2007.

ALCÂNTARA, J.M. et al., Composição química dos óleos essenciais de espécies de Aniba e Licaria e suas atividades antioxidantes e antiagregante plaquetária. Química Nova, v. 33, n.1, p. 141-5, 2010.

ALMEIDA, M.R. Estudo farmacológico do extrato aquoso bruto e óleo essencial das folhas de Myrcia sylvatica (G.Mey.) DC. 2014. 81 p. Dissertação (Mestrado em Recursos Naturais da Amazônia) Universidade Federal do Oeste do Pará, Santarém.

BARRETO, C.F. Aedes aegypti- Resistência a inseticidas químicos e novas alternativas de controle. Revista Eletrônica da Faculdade de Montes Belos, v.1, n. 2, p. 62-73, 2005.

ANDRADE, A.; PINTO, S.C.; OLIVEIRA, R.S.(org). Animais de Laboratório: criação e experimentação. Rio de Janeiro: Editora Fiocruz, 2002

BATISTA, N.Y. et al., Avaliação da toxicidade do extrato aquoso e óleo essencial Myrcia sylvatica (G.Mey.) DC. Frente a Artemia salina. In: REUNIÃO ANUAL DA SOCIEDADE BRASILEIRA PARA O PROGRESSO DA CIÊNCIA(SPBC), 62., 2010. Natal. Anais. Natal, 2010.

BHATT, S. et al., The global distribution and burden of dengue. Nature, v. 496, n. 7446, p. 504-7, 2013.

BOAS, G. de K.V.; GADELHA, C.A.G. Oportunidades na indústria de medicamentos e a lógica do desenvolvimento local baseado nos biomas brasileiros: bases para a discussão de uma política nacional. Caderno de Saúde Pública.v.23, n.4,p.179-293,2007.

BRAGA, I.A.; VALLED, D. Aedes aegypti: inseticidas, mecanismos de ação e resistência. Revista de Epidemiologia e Saúde, v. 16, n. 4, p.179-293, 2007.

BRASIL. Ministério da Saúde. Febre Chikunguya: Manejo clínico. 2014a.

BRASIL. Ministério da Saúde. Monitoramento dos casos de dengue até a Semana Epidemiológica (SE) 41 e febre de chikungunya até a SE 42 de 2014. Boletins Epidemiológicos, v. 45, n. 26, p. 1-6, 2014b.

CEPLENAU, F. Validation and aplication of three bench-top bioassay for screennig of crude plant extracts and subsequent activity-guide isoalation. 1993, 186 p. Tese (Doutorado em Ciências) - Faculdade de Lausanni, Lausanni.

CERQUEIRA, M.D. et al., Variação sazonal da composição química do óleo essencial de Myrcia salzmanni Berg. (Myrtaceae). Química Nova, v. 32, n. 6, p. 1544-8, 2009.

CHENG, S.S. et al., Chemical compositions and larvicidal activities of leaf essential oils from two Eucalyptus species. Bioresource Technology, v. 100, p. 452-6,

Rev. Bras. PI. Med., Campinas, v.18, n.1, p.19-26, 2016. 
2009.

CONSOLI, R.A.G.B.; OLIVEIRA, R.L. 1994. Principais mosquitos de importância sanitária no Brasil. Rio de Janeiro: Fiocruz, 1994. 228 p.

COSTA, E.V. et al., Chemical composition and antimicrobial activity of the essential oils of the Amazon Guatteeriops species. Phytochemistry, v. 69, p. 1895- 9, 2008.

COUTINHO, D.F. et al., Composition and molluscicidal activity of the essential oil from the stem bark of Ocotea bracteosa (Meisn.) Mez. Journal Essential Oil Research, v. 19, p. 482-4, 2007.

DAVID, J.P. et al., Lignanas e triterpenos do extrato citotóxico de Eriope blanchetii. Química Nova, v. 24, n. 6, p. 730-3, 2001.

DIAS,C.N.; MORAES, D.F.C. Essential oil and their compounds as Aedes aegypti L. (Diptera: Culicidae) larvicides: Review. Parasitology Resarch, v.113, p. 565-592, 2014.

DOLABELLA, M. Triagem in vitro para atividade antitumoral e anti-Tripanossoma cruzi de extratos vegetais, produtos naturais e substâncias sintéticas. 1997. 128 p. Dissertação (Mestrado) - Universidade Federal de Minas Gerais, Belo Horizonte.

DONATO, A.; MORRETES, B. Morfoanatomia foliar de Myrcia multiflora (Lam.) DC- Myrtaceae. Revista Brasileira de Plantas Medicinais, v. 13, n.1, p. 43-51, 2011.

DUARTE, A.R. Variabilidade química dos óleos essenciais e do teor fenóis em folhas e frutos de jabuticaba (Myrciaria cauliflora). 2012. 72 p. Tese (Doutorado em Química) - Instituto de Química, Universidade Federal de Goiás, Goiânia.

EDRES, A.E. Pharmaceutical and therapeutic potentials of essential oils and their individual volatile constituents: Review. Phytoterapy Reseach, v. 21, n. 4, p.308-323, 2007.

EL-MENSSHAWI, B.S. et al., Screening of natural products for therapeutic activity against solid tumors. Indian Journal of Experimental Biology, v.48, n.3, p.258-64, 2010.

FARMACOPEIA BRASILEIRA . 5.ed. Brasilia: Vigilância Sanitária Nacional, 2010.

FONTES, J.E.N. et al., Atividade larvicida do óleo essencial de folhas frescas de Myrcia Ludina e Myrcia guianensis (Myrtaceae) contra o Aedes aegypti. In: REUNIÃO ANUAL DA SOCIEDADE BRASILEIRA PARA O PROGRESSO A CIÊNCIA (SBPC), 63., 2011, Florianopólis. Anais. Florianopólis, 2011.

GUIMARÃES, L.G. de L. et al., Atividades antioxidante e fungitóxica do óleo essencial de capim-limão e do citral. Revista Ciência Agronômica, v.42, n.2, p. 46472, 2011.

HARADA, T.N. Correlação entre os ensaios de citotoxicidade em Artemia salina leach e atividade antineoplásica sobre linhagens de células tumorais para algumas classes de produtos naturais. 2009. 92 p. Dissertação (Mestrado em Saúde e Desenvolvimento na Região Centro-Oeste) - Universidade Federal de Mato Grosso do Sul, Campo Grande.

JOHARCHI, M.R.; AMIRI, M.S. Taxonomic evaluation of misidentification of crude herbal drugs marked in Iran. Avicenna Journal of Phytomedicine, v.2,n.2,p.105-112, 2012.
KANWAR, A.S. Artemia salina - a marine animal for simple and rapid biological assays. Jornal of Chiense Clinical Medicine, v. 2, n. 4, p. 236-240, 2007.

LIMBERGER, R.P. et al., Óleos voláteis de espécies de Myrcia nativas do Rio Grande do Sul. Química Nova, v. 27, n. 6, p. 916-19, 2004.

LUNA, J.S. et al., A study of the larvicidal and molluscicidal activities of some medicinal plants from northeast Brazil. Journal of Ethnopharmacology, v.97, n.2, p.199-206, 2005.

LUNGUINO, D. Estudo da antitumoral e efeitos toxicológicos do óleo essencial das folhas de Xylopia frutescens Aubl. (Annonaceae). 2012. 137 p. Dissertação (Mestrado em Produtos Naturais e Sintéticos Bioativos) - Universidade Federal de Paraíba, João Pessoa.

MCLAUGHLIN, J.L. et al., The Use of Biological Assays to Evaluate Botanicals. Journal Drug Information, v. 32, p. 513-24, 1998.

MEYER, B.N. et al., Artemia salina: a convenient general bioassay for active plant constituents. Journal of Medicine Plant Research, v. 45, p.31-4,1982.

MONTEIRO, M.M.M.; VASCONCELOS, A.S.; LAVOR, P.L.; LIMA, M.A.A.; SANTIAGO, G.M.P. Composição química dos óleos essencias de Eugenia uniflora e Myrcia ovate. In: REUNIÃO DE INICIAÇÃO CIENTÍFICA E PÓS-GRADUAÇÃO, 31, 2011, Fortaleza. Anais, Fortaleza, 2011.

MORRINSON T.; PFLIFFER, J. Reemergece of Chikunguya. Journal Virology, v. 88, n. 20, p. 116447, 2014.

NIST 05. Mass spectral library (NIST/EPA/NIH). Gaithersburg: National Institute of Standards and Technology, 2005.

PARRA, A.L. et al., Comparative study of the assay of Artemia salina $\mathrm{L}$. and the estimate of the medium lethal dose (LD50 value) in mice, to determine oral acute toxicicty of plant extracts. Planta Medica, v.8, n.5, p.395-400, 2001.

PORTO, K.R.A.; et al., Atividade larvicida do óleo de Anacardium humile Saint Hill sobre Aedes aegypti (Linnaeus, 1762) (Diptera, Culicidae). Revista da Sociedade Brasileira de Medicina Tropical, v. 4, n. 6, p. 586-9, 2008.

RODRIGUES, A.R.S. Caracterização da resistência de joaninhas predadoras ao lambdacialotrina. 2012. 162p. Tese (Doutorado em Entomologia Agrícola) Universidade Federal Rural de Pernambuco, Recife.

SÁ, F.A.S.; et al., Essential oil in aerial parts of Myrcia tomentosa composition and variability. Revista Brasileira de Farmacognosia, v. 22, n. 6, p. 12331240, 2012.

SABINO, J.F.P.; et al., Análise e discriminação dos fenótipos de Lippia graveolens HBK da Guatemala por microextração em fase sólida, CG/EM e análise multivariada. Química Nova, v. 35, n. 2, p. 97-101, 2012.

SANTOS, M.A.V. de. Aedes aegypti (Diptera:Culicidae): Estudos Populacionais e Estratégias Integradas para Controle Vetorial em Municípios da Região Metropolitana do Recife, no Período de 2001 A 2007. 2008. 218p. Tese (Doutorado em Saúde Pública) - Centro de Pesquisas Aggeu Magalhães, Fundação Oswaldo Cruz, Recife. 
SANTOS, R.P.; et al., Chemical composition and larvicidal activity of the essential oil of Cordia leucomalloides and Cordia curassavica form the Northeast Brazil. Journal of the Brazilian Chemical Society, v.17, n. 5, p.10271030, 2006.

SCHRIPSEMA, J.; DAGNINO, D.; GOSMANN, G. Alcalóides indólicos. In: SIMÕES, C.M.O.; SCHENKEL, E.P.; GOSMANN, G.; MELLO; MENTZ, L.A.; PETROVICK, P.R. Farmacognosia: da planta ao medicamento. 5.ed. Porto Alegre/Florianópolis: UFRGS/ UFSC, 2004. p.819-846.

SHERER, R.; et al., . Composição e atividades antioxidante e antimicrobiana dos óleos essenciais de cravo-daíndia, citronela e palmarosa. Revista Brasileira de Plantas Medicinais, v.11, n.4, p.442-49, 2009.

SILVA, F.K.S. Sinopse e composição química dos óleos essenciais de espécies de Myrtaceae comercializadas como pedra-ume-caá em BelémPará. 2012. 68p. Dissertação (Mestrado em Botânica) - Universidade Federal da Amazônia, Manaus.

SILVA, W.J. Atividade larvicida do óleo essencial de plantas existentes no estado de Sergipe contra Aedes aegypti Linn. 2006. 81p. Dissertação (Mestrado em Desenvolvimento e Meio Ambiente) - Universidade Federal de Sergipe, São Cristovão.

SILVA, W.J.; et al., Effects of essential oils on Aedes aegypti larvae: alternatives to environmentally safe insecticides. Bioresource Technology, v. 99, n.8, p. 3251-5, 2008.

SILVEIRA, P.F. et al., Farmacovigilância e reações adversas às plantas medicinais e fitoterápicos: uma realidade. Revista Brasileira de Farmacognosia, v.18, p.618-26, 2008

SIMAS, N.K.; et al., Produtos naturais para o controle da transmissão da dengue - atividade larvicida de Myroxylon balsamum (óleo vermelho) e de terpenóides e fenilpropanóides. Química Nova, v. 27, n.1, p. 46-9, 2004.

SIQUEIRA, J.M.; et al., Estudo fitoquímico de Unonopsis lindmanii - Annonaceae, biomonitorado pelo ensaio de toxicidade sobre a Artemia salina leach. Química Nova, v. 21, n 5, p. 557-9, 1998.

TROPICOS ORG. Nomenclatural and specimens database of the Missouri Botanical Garden. 2013. Diponível em: <htpp://www.tropicos.org>. Acessado em 15 de mar de 2013.

VALTER, J.L.; et al., Variação química no óleo essencial das folhas de seis indivíduos de Duguetia furfuracea (Annonaceae). Revista Brasileira de Farmacognosia, v. 18, n. 3, 373-8, 2008.

WHO. World Health Organization. Dengue bulletin: Situation of dengue/dengue hemorrhagic fever in SEA countries. 2004.

WHO. World Health Organization. Dengue: guidelines for diagnosis, treatment, prevention and control. Geneva, 2009.

ZANLUCA, C.; et al., The first report of autochtonous transmission of Zika virus in Brazil. Memorando do Instituto Oswaldo Cruz, v.110, n.4, p.569-72, 2015.

ZOGHBI, M.G.B.; et al., Essential oils from three Myrcia species. Flavour Fragrance Journal, v. 18, p. 421-24, 2002. 